06

\title{
Эволюция структуры AlCoCrFeNi высокоэнтропийного сплава при облучении импульсным электронным пучком
}

\author{
(C) Ю.Ф. Иванов, ${ }^{1}$ В.Е. Громов, ${ }^{2}$ С.В. Коновалов, ${ }^{3}$ Ю.А. Шлярова ${ }^{2}$ \\ ${ }^{1}$ Институт сильноточной электроники СО РАН, \\ 634055 Томск, Россия \\ ${ }^{2}$ Сибирский государственный индустриальный университет, \\ 654007 Новокузнецк, Россия \\ ${ }^{3}$ Самарский национальный исследовательский университет им. академика С.П. Королева, \\ 443086 Самара, Россия \\ E-mail: gromov@physics.sibsiu.ru
}

Поступило в Редакцию 7 июля 2021 г.

В окончательной редакции 12 августа 2021 г.

Принято к публикации 24 августа 2021 г.

Методами современного физического материаловедения изучено изменение структуры высокоэнтропийного сплава $\mathrm{AlCoCrFeNi} \mathrm{неэквиатомного} \mathrm{состава,} \mathrm{полученного} \mathrm{методом} \mathrm{аддитивной} \mathrm{технологии} \mathrm{при} \mathrm{облучении}$ тремя пучками электронов с плотностью энергии $10-30 \mathrm{~J} / \mathrm{cm}^{2}$, длительностью $50 \mu \mathrm{s}$, частотой $0.3 \mathrm{~s}^{-1}$. В исходном состоянии сплав имел дендритное строение, указывающее на неоднородное распределение элементов. Показано, что электронно-пучковая обработка формирует структуру высокоскоростной ячеистой кристаллизации с размером ячеек 100-200 nm, вдоль границ которых располагаются наноразмерные $(15-30 \mathrm{~nm})$ включения второй фазы, обогащенные атомами $\mathrm{Cr}$ и $\mathrm{Fe}$.

Ключевые слова: высокоэнтропийный сплав, электронно-пучковая обработка, структура, фазовый состав.

DOI: 10.21883/JTF.2021.12.51762.205-21

В последние два десятилетия внимание исследователей в области физического материаловедения привлечено к изучению высокоэнтропийных сплавов (ВЭС), обладающих уникальными свойствами по сравнению с традиционными легированными сплавами [1]. Высокоэнтропийные сплавы содержат 5 и более элементов с содержанием от 5 до 35\% [2,3], что должно приводить к неоднородному их распределению в объеме.

Одним из наиболее перспективных методов получения ВЭС является новая аддитивная технология (wire arc additive manufacturing (WAAM)) [4]. BЭC $\mathrm{AlCoCrFeNi,}$ изготовленный этим методом, имеет ярко выраженное дендритное строение, что указывает на неоднородное распределение легирующих элементов в объеме слитка [5]. Одним из способов, позволяющих осуществить гомогенизацию сплава является метод, основанный на облучении поверхности образцов низкоэнергетическим интенсивным импульсным электронным пучком. Сверхвысокие (до $10^{9} \mathrm{~K} / \mathrm{s}$ ) скорости нагрева сравнительно тонкого (десятки-сотни $\mu \mathrm{m}$ ) поверхностного слоя до температуры плавления и последующая высокоскоростная кристаллизация расплава позволяют формировать субмикро- нанокристаллическую структуру, характеризующуюся высокой степенью однородности распределения химических элементов [6,7]. В настоящей работе рассмотрено влияние плотности энергии пучка электронов на структурно-фазовое состояние поверхностного слоя ВЭС.

Образцы ВЭС AlCoCrFeNi были сформированы по аддитивной технологии (WAAM) в атмосфере $\operatorname{Ar}(99.99 \%)$.
Сплав содержит алюминия 36.5 at.\%, никеля 33.7 at.\%, железа 16.4 at.\%, хрома 8.6 at.\% и кобальта 4.9 at.\%, т. е. полученный материал следует отнести к ВЭС неэквиатомного состава.

Режимы нанесения слоев не отличались от описанных в [5]. Образцы подвергались облучению импульсным электронным пучком с параметрами: энергия ускоренных электронов $18 \mathrm{keV}$, плотность энергии пучка электронов $10-30 \mathrm{~J} / \mathrm{cm}^{2}$, длительность импульса пучка $50 \mu \mathrm{s}$, частота следования импульсов $0.3 \mathrm{~s}^{-1}$, количество импульсов облучения 3, облучение проводили при остаточном давлении инертного газа (аргон) в рабочей камере установки $2 \cdot 10^{-2} \mathrm{~Pa}$.

Структуру и элементный состав образцов изучали методами сканирующей электронной микроскопии (приборы LEO EVO 50 и TESCAN VEGA, оснащенные энергодисперсионным анализатором INCA Energy). Дефектную субструктуру и распределение химических элементов изучали методами просвечивающей электронной микроскопии (прибор JEOL JEM-2100) [8]. Объекты исследования (фольги толщиной 150-200 nm) для просвечивающего электронного микроскопа изготавливали методом ионного травления (установка Ion Slicer (EM09100IS), аргон) пластинок, вырезанных из объемного слитка ВЭС. Структуру и элементный состав анализировали в слое толщиной 5-10 $\mu \mathrm{m}$, примыкающем к поверхности облучения.

Облучение ВЭС импульсным электронным пучком с плотностью энергии пучка электронов $E_{S}=10 \mathrm{~J} / \mathrm{cm}^{2}$ не приводит к разрушению структуры дендритной кри- 


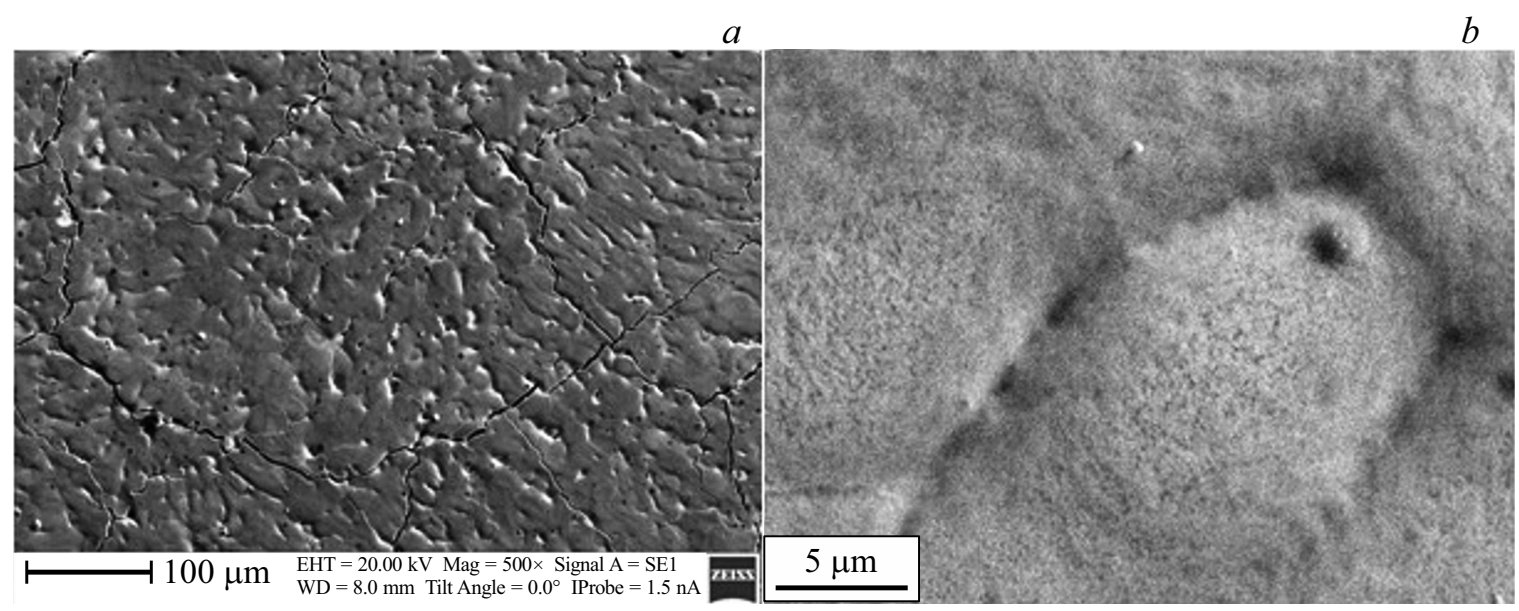

Рис. 1. Электронно-микроскопическое изображение структуры ВЭС, формирующейся в результате облучения импульсным электронным пучком $\left(20 \mathrm{~J} / \mathrm{cm}^{2}\right)$.

сталлизации, характерной для сплава в исходном состоянии [5]. Этот факт свидетельствует об отсутствии плавления поверхностного слоя облученных образцов. Жидкофазное преобразование структуры поверхностного слоя ВЭС обнаруживается лишь в приграничных областях зеренной (дендритной) структуры. Высокоскоростное преобразование структуры сопровождается формированием прослоек, имеющих субмикро- нанокристаллическую структуру с размером кристаллитов $100-200 \mathrm{~nm}$.

Исследования элементного состава дендритов и междендритных пространств поверхностного слоя, выполненные методами микрорентгеноспектрального анализа, показали, что междендритные пространства обогащены химическими элементами $\mathrm{Al}, \mathrm{Ni}$ и $\mathrm{Fe}$. Дендриты обогащены преимущественно атомами хрома. Атомы кобальта распределены равномерно по объему слитка. Наиболее ликвирующим элементом сплава является алюминий (коэффициент ликвации $\delta=9.2$ ), наименее ликвирующим является кобальт $(\delta=2.1)$.

Облучение ВЭС импульсным электронным пучком с плотностью энергии пучка электронов $E_{S}=20 \mathrm{~J} / \mathrm{cm}^{2}$ приводит к частичному разрушению структуры дендритной кристаллизации (рис. $1, a)$. Этот факт свидетельствует о плавлении поверхностного слоя облученных образцов. Жидкофазное преобразование структуры поверхностного слоя ВЭС сопровождается формированием в объеме зерен нанокристаллической структуры (рис. $1, b)$.

Анализ хрупких изломов показал, что поверхностный слой толщиной $\approx 15 \mu \mathrm{m}$, сформированный после облучения, имеет субмикронанокристаллическую структуру. Его толщина увеличивается с ростом плотности энергии пучка электронов и достигает $\approx 20 \mu \mathrm{m}$ при $E_{S}=30 \mathrm{~J} / \mathrm{cm}^{2}$. В нем формируется структура высокоскоростной ячеистой кристаллизации. Объем ячеек кристаллизации обогащен атомами алюминия, никеля и железа. В стыках и вдоль границ ячеек располагаются включения второй фазы, которые обогащены преимущественно атомами хрома. Размер ячеек кристаллизации составляет 100-200 nm; размер включений, расположенных в стыках ячеек - 20-25 nm; расположенных вдоль границ ячеек - 10-15 nm.

Исследования элементного состава ячеек высокоскоростной кристаллизации и частиц второй фазы (рис. 2, см. таблицу) дают основание заключить, что ячейки высокоскоростной кристаллизации (области анализа, обозначенные надписями спектр 1-5) обогащены химическими элементами $\mathrm{Al}$ и $\mathrm{Ni}$. Частицы второй фазы, расположенные на границах и в стыках ячеек кристаллизации (области анализа, обозначенные надписями спектр 8-11) обогащены преимущественно атомами $\mathrm{Cr}$ и Fe. Атомы Co распределены равномерно по объему поверхностного слоя. Наиболее ликвирующим элементом поверхностного слоя сплава, обработанного импульсным электронным пучком $\left(20 \mathrm{~J} / \mathrm{cm}^{2}, 50 \mu \mathrm{s}\right.$, 3 pulses, $0.3 \mathrm{~s}^{-1}$ ), является $\mathrm{Cr}$ (коэффициент ликвации $\delta=5.4)$, наименее ликвирующим является Со $(\delta=1.9)$. Элементный состав зон спектров 6, 7, 12 трудно сопоставить с элементным составом зон, расположенных в объеме ячеек или на их границе. Можно предположить, что данные зоны относятся к смешанным, т.е. частично содержат в себе материал объема ячеек и материал их границ.

При плотности энергии пучка электронов $30 \mathrm{~J} / \mathrm{cm}^{2}$ также формируется поверхностный слой, имеющий структуру высокоскоростной кристаллизации ячеистого типа. Ячейки кристаллизации имеют округлую форму. Размер ячеек изменяется в пределах от 100 до $150 \mathrm{~nm}$. Ячейки окаймлены прослойками второй фазы. Толщина прослоек изменяется в пределах 15-30 nm. Объем ячеек обогащен химическими элементами $\mathrm{Al}$ и $\mathrm{Ni}$. Атомы хрома и железа преимущественно формируют частицы второй фазы. Атомы кобальта равномерно распределены по объему модифицированного слоя.

Наиболее ликвирующим элементом поверхностного слоя сплава является $\mathrm{Cr}$ (коэффициент ликва- 

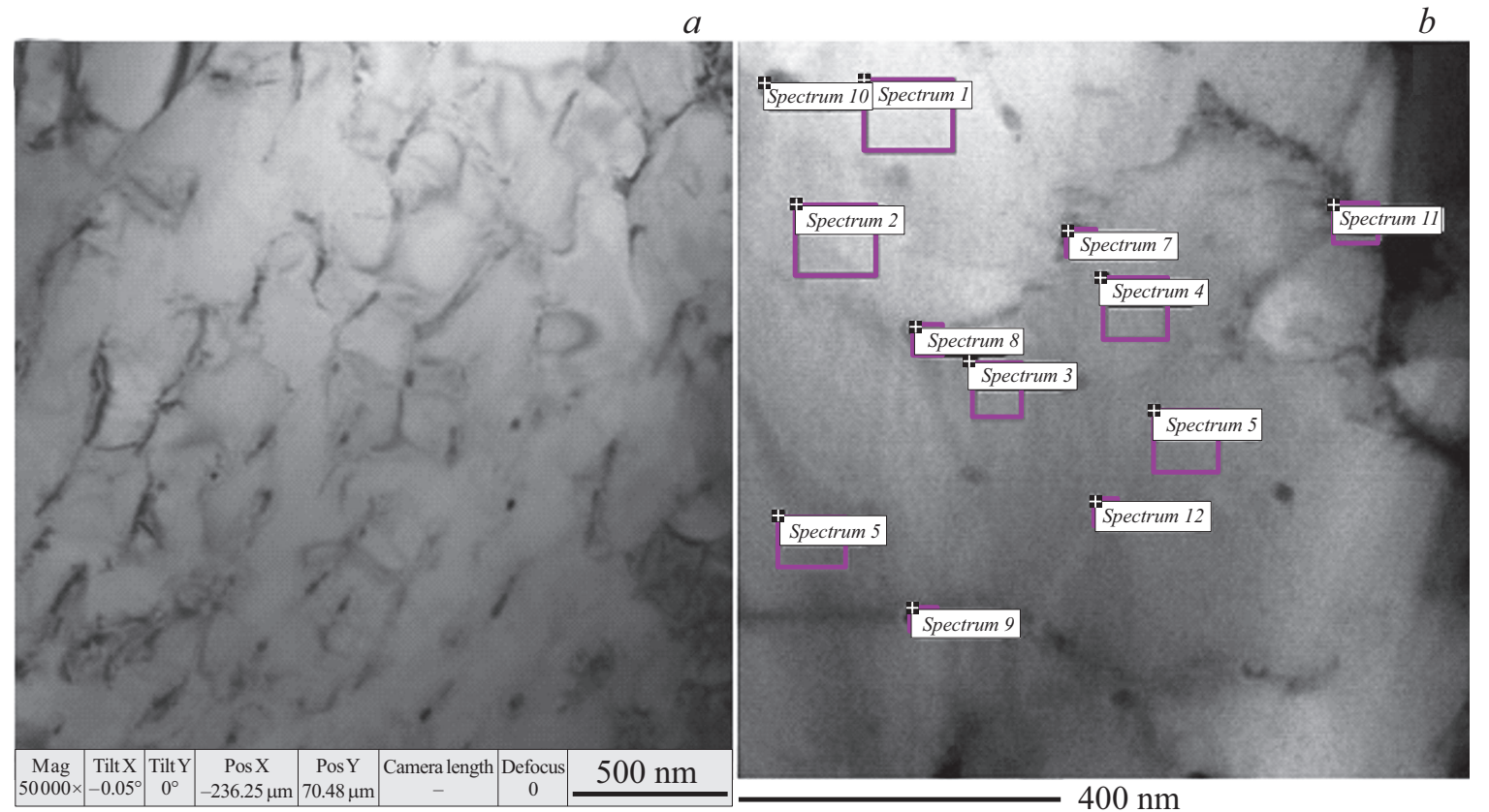

Рис. 2. Электронно-микроскопическое изображение участка фольги, полученное методом ТЕМ $(a)$ и STEM (b) анализа. На $(b)$ обозначены участки микрорентгеноспектрального анализа фольги. Облучение проводили при плотности энергии пучка электронов $20 \mathrm{~J} / \mathrm{cm}^{2}$.

Результаты элементного анализа (at.\%) участков фольги, представленного на рис. $2, b$

\begin{tabular}{|c|c|c|c|c|c|}
\hline Спектр & $\mathrm{Al}$ & $\mathrm{Cr}$ & $\mathrm{Fe}$ & Co & $\mathrm{Ni}$ \\
\hline 1 & 38.9 & 5.9 & 10.4 & 2.9 & 27.2 \\
\hline 2 & 39.0 & 5.2 & 12.5 & 3.7 & 25.7 \\
\hline 3 & 36.8 & 4.3 & 11.8 & 4.9 & 29.7 \\
\hline 4 & 41.3 & 5.3 & 11.7 & 4.7 & 27.7 \\
\hline 5 & 40.6 & 5.0 & 12.0 & 4.4 & 29.1 \\
\hline 6 & 38.0 & 5.0 & 11.9 & 3.5 & 25.4 \\
\hline 7 & 25.2 & 17.4 & 14.4 & 4.0 & 19.8 \\
\hline 8 & 17.5 & 23.3 & 23.5 & 3.2 & 12.3 \\
\hline 9 & 24.5 & 17.5 & 20.3 & 5.6 & 21.5 \\
\hline 10 & 15.8 & 16.1 & 21.0 & 3.8 & 14.6 \\
\hline 11 & 15.2 & 21.9 & 22.4 & 4.3 & 20.3 \\
\hline 12 & 28.7 & 15.7 & 18.5 & 4.3 & 18.8 \\
\hline Среднее значение & 30.1 & 11.9 & 15.9 & 4.1 & 22.7 \\
\hline Максимальное значение & 41.3 & 23.3 & 23.5 & 5.6 & 29.7 \\
\hline Минимальное значение & 15.2 & 4.3 & 10.4 & 2.9 & 12.3 \\
\hline$\delta(\max / \min )$ & 2.7 & 5.4 & 2.3 & 1.9 & 2.4 \\
\hline
\end{tabular}

ции $\delta=10.5)$, наименее ликвирующим является Со $(\delta=1.6)$. Обобщающие результаты, полученные при

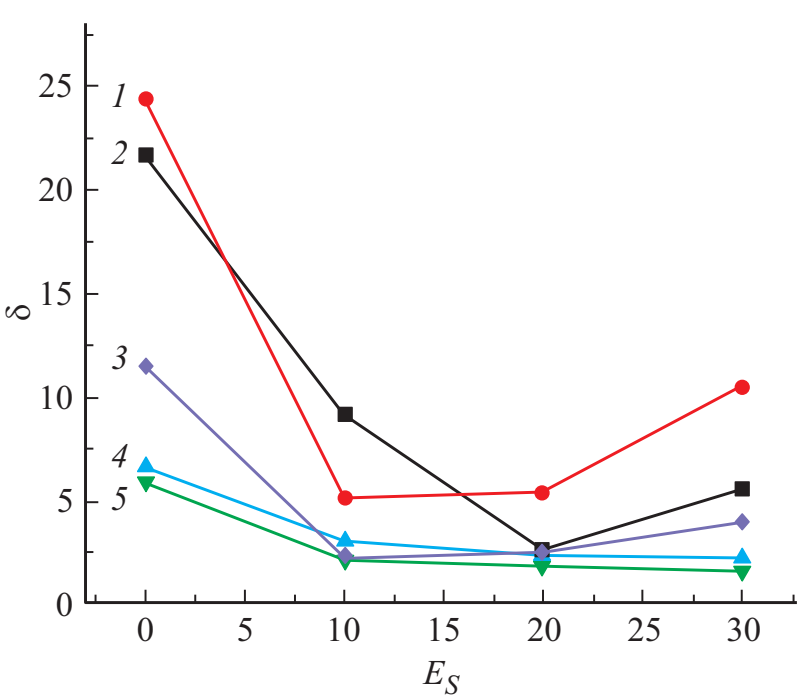

Рис. 3. Зависимость коэффициента неоднородности распределения химических элементов, формирующих ВЭС, от плотности энергии пучка электронов; $1-\mathrm{Cr}, 2-\mathrm{Al}, 3-\mathrm{Ni}, 4-\mathrm{Fe}$, $5-$ Co.

микрорентгеноспектральном анализе ВЭС в исходном состоянии и после облучения импульсным электронным пучком, характеризующие степень неоднородности распределения легирующих элементов в поверхностном слое, приведены на рис. 3. Наиболее ликвирующими элементами сплава являются хром и алюминий. Облучение ВЭС импульсным электронным пучком способствует гомогенизации сплава. Наиболее высокий уровень 
однородности распределения химических элементов в сплаве достигается при облучении импульсным электронным пучком с плотностью энергии пучка электронов $20 \mathrm{~J} / \mathrm{cm}^{2}$.

Облучение ВЭС импульсным электронным пучком приводит к формированию структуры высокоскоростной ячеистой кристаллизации. Размер ячеек изменяется в пределах от 100 до $200 \mathrm{~nm}$. Вдоль границ ячеек располагаются наноразмерные $(15-30 \mathrm{~nm})$ включения второй фазы, обогащенные атомами $\mathrm{Cr}$ и $\mathrm{Fe}$. Показано, что ВЭС характеризуется высокой степенью неоднородности распределения химических элементов, формирующих сплав. Наиболее ликвирующими элементами сплава являются хром и алюминий. Облучение ВЭС импульсным электронным пучком способствует гомогенизации сплава. Выявлен режим облучения, позволяющий формировать поверхностный слой, характеризующийся наиболее высоким уровнем однородности распределения химических элементов в сплаве.

\section{Финансирование работы}

Исследование выполнено при финансовой поддержке Российского научного фонда в рамках научного проекта № 20-19-00452.

\section{Конфликт интересов}

Авторы заявляют, что у них нет конфликта интересов.

\section{Список литературы}

[1] Y. Zhang. High-Entropy Materials. A Brief Introduction (Springer Nature, Singapore, 2019), $152 \mathrm{p}$. DOI: $10.1007 / 978-981-13-8526-1$

[2] C.C. Tung, J.W. Yeh, T.T. Shun, S.K. Chen, Y.S. Huang, H.C. Chen. Mater. Lett., 61 (1), 1 (2007). https://doi.org/10.1016/j.matlet.2006.03.140

[3] Y.J. Zhou, Y. Zhang, T.N. Kim, G.L. Chen. Mater. Lett., 62 (1718), 2673 (2008). https://doi.org/10.1016/j.matlet.2008.01.011

[4] Q. Shen, X. Kong, X. Chen. J. Mater. Sci. Technol., 74, 136 (2021). 10.1016/j.jmst.2020.10.037

[5] K.A. Osintsev, S.V. Konovalov, A.M. Glezer, V.E. Gromov, Yu.F. Ivanov, I.A. Panchenko, R.V. Sundeev. Mater. Lett., 294, 129717 (2021). https://doi.org/10.1016/j.matlet.2021.129717.

[6] Yu.F. Ivanov, D.V. Zaguliaev, A.M. Glezer, V.E. Gromov, A.A. Abaturova, A.A. Leonov, A.P. Semin, R.V. Sundeev. Mater. Lett., 275, 128105 (2020). https://doi.org/10.1016/j.matlet.2020.128105

[7] B. Gao, Y. Hao, W.F. Zhuang, G.F. Tu, W.X. Shi, S.W. Li, S.Z. Hao, C. Dong, M.C. Li. Physics Proc., 18, 187 (2011). https://doi.org/10.1016/j.phpro.2011.06.079

[8] F.R. Egerton. Physical Principles of Electron Microscopy (Springer International Publishing, Basel, 2016), 202 p. 